\title{
LITERATURA SURDA E CONTEMPORANEIDADE: CONTRIBUIÇÕES PARA O ESTUDO DA VISUAL VERNACULAR
}

\author{
DEAF LITERATURE AND CONTEMPORANEITY: CONTRIBUTIONS TO THE \\ VERNACULAR VISUAL STUDY
}

\author{
Danielle Cristina Mendes Pereira Ramos ${ }^{1}$, Bruno Abrahão \\ 1 Universidade Federal do Rio de Janeiro (UFRJ), Rio de Janeiro, RJ, Brasil \\ dcmendes28@gmail.com \\ 2 Universidade Federal de Santa Catarina (UFSC), Florianópolis, SC, Brasil \\ bruno@letras.ufrj.br
}

Recebido em: 23 abr. 2018

Aceito em: 24 mai. 2018

Resumo: Este artigo tem como objetivo refletir sobre aspectos específicos da categoria da literatura surda chamada Visual Vernacular. Nossa proposta é estudar as suas especificidades e compreender os seus modos de organização estética. Além disso, intentamos pensá-la no âmbito de sua inserção no cenário cultural e artístico da contemporaneidade, pois acreditamos na necessidade de refletir sobre as manifestações literárias concernentes às expressões culturais surdas e às línguas de sinais em uma perspectiva ampla, que não a restrinja à mera leitura impressionista, mas que a considere dentro de um contexto pós-moderno de produção e de circulação cultural no qual ela ocupa um lugar, para além da dimensão solipsista. Para tanto, três conceitos contribuirão para o nosso esteio teórico: a noção de Contemporaneidade, a partir da proposta de Terry Smith (2013), que a percebe em uma dimensão plural, política e em construção; a percepção da inespecificidade da forma artística contemporânea, postulada por Florência Garramuño (2014), que nos ajudará a pensar sobre a experimentação estética pertinente à literatura surda, em sua dimensão tridimensional e performática; e a visão de hibridismo cultural proposta por Néstor Garcia Canclini (2006), que rechaça a possibilidade de pureza cultural e a contrapõe à presença da labilidade das fronteiras culturais e do deslocamento dos bens simbólico na pós-modernidade.

Palavras-Chave: Literatura Surda. Contemporaneidade. Visual Vernacular.

\begin{abstract}
This article aims to study specific aspects of Deaf Literature's category namely Visual Vernacular. Our proposal is to study the pertinent specificities of such literary expressions and to understand their modes of aesthetic organization. In addition, we try to think of them in the context of their insertion in the cultural and artistic scene of Contemporaneity, as we believe that it is necessary to reflect on literary manifestations concerning deaf cultural expressions and sign languages in a broad perspective, that does not restrict it to the mere impressionist reading, but consider it inside a postmodern context of production and cultural circulation in which it occupies a place beyond the solipsistic dimension. To do so, three concepts will contribute to our theoretical support: the notion of Contemporaneity, based on the proposal of Terry Smith (2013), who perceives it in a plural, political and as a work in progress; the contemporary artistic form's non-specificity, postulated by Florencia Garramuño (2014), which will help us to think about the aesthetic experimentation pertinent to deaf literature, in its three-dimensional and performative dimension; and the concept of cultural hybridism proposed by Néstor Garcia Canclini (2006), which rejects the possibility of cultural pureness and contrasts it with the lability of cultural boundaries and the displacement of symbolic objects in postmodernity.
\end{abstract}

Keywords: Deaf Literature. Contemporaneity. Visual Vernacular. 


\section{Introdução}

(...) A arte nunca deve ser pura. Ela nunca deve pedir isso. Quanto mais cruzada e impura ela for, mais ela nos tocará das maneiras mais inesperadas.

Raymond Luczak, artista surdo

O pioneirismo nos estudos voltados para a Língua de Sinais deu-se, no Brasil, em torno do trabalho da professora e pesquisadora de Linguística Lucinda Ferreira Brito, na Universidade Federal do Rio de Janeiro, cujas pesquisas e orientações de trabalhos destacavam-se já nas décadas de oitenta e de noventa do século XX. Em relação a esta década, podemos também apontar a emergência, na Universidade Federal do Rio Grande do Sul, do Núcleo de Pesquisas em Políticas Educacionais para Surdos, o NUPPES.

Liderado por Carlos Skliar, o grupo interessava-se por temas e problemas pertinentes à educação de surdos e por questões que envolviam as identidades e as culturas surdas, estudadas pela chave dos Estudos Culturais, sobretudo com base no pensamento de Homi Bhabha e de Stuart Hall. Foi Skliar que, a partir das propostas do NUPPES, indicou o conceito de "Estudos Surdos" como "um programa de pesquisa em educação, pelo qual as identidades, as línguas, os projetos educacionais, a história, a arte, as comunidades e as culturas surdas são focalizados e entendidos a partir da diferença, a partir de seu reconhecimento político" (SKLIAR, 2013, p. 5).

Com as políticas educacionais voltadas para os surdos, implantadas na primeira década dos anos 2000, e a consequente abertura de cursos de Letras-LIBRAS (Língua Brasileira de Sinais), percebemos a possibilidade de ampliação do conceito "Estudos Surdos", quando este alarga o seu alcance e passa a abarcar os estudos linguísticos e literários, em complemento às pesquisas tecidas pelo foco específico da Educação. Ao abranger estudos referenciados teoricamente na área de Letras, abrese espaço tanto para a construção de novos olhares acerca de seus objetos, como para a verticalização das pesquisas já constituídas, pelo alargamento e aprofundamento dos diálogos interdisciplinares. Desse modo, pensamos os Estudos 
Surdos não apenas como um programa de pesquisa, mas como um campo epistemológico que se amplia e se complexifica.

Neste trabalho, interessa-nos pensar pela perspectiva dos Estudos Surdos questões pertinentes à literatura surda produzida em línguas de sinais ${ }^{1}$. Nossa proposição aqui é pensá-la através do estudo de uma categoria literária específica, a Visual Vernacular, ou VV. Nós também nos deteremos na exploração de uma perspectiva teórica que pretende analisar os vínculos entre a poética da VV - no sentido da organização de seus elementos estéticos - e um cenário cultural, político e social específico, o da Contemporaneidade, conceito que entendemos pelo suporte do olhar de Terry Smith (2013).

No que tange à marcação histórica, pode-se afirmar o consenso sobre o começo da Contemporaneidade situado entre dois acontecimentos emblemáticos de fins do século XX: a queda do muro de Berlim, em 1989, e o fim da Guerra Fria, em 1991. O contexto organizado delineou configurações que abriram espaço para a arquitetura da globalização e de suas marcas, como a emergência de Novas Tecnologias de Informação e Comunicação (TICs), a liquefação do capital e o surgimento de uma nova percepção da relação espaço-tempo. Além disso, há a mudança de paradigma na produção cultural, com deslocamentos sensíveis das funções de receptor e produtor, em uma dinâmica criativa que retira aquele da posição passiva e abre espaço para a sua criação, possibilitada por formas inéditas de elaboração artística e de divulgação disponibilizadas pelas TICs.

Em que pese a supracitada marcação histórica, cremos que seja mais produtivo pensar a Contemporaneidade de modo mais fluido e plural, não a atrelando a um recorte temporal cristalizado, mas a compreendendo como derivada de redes contextuais variáveis. Assim, existem várias contemporaneidades simultâneas, mas não homogêneas.

Nesse sentido, Smith (2013) propõe apreensões distintas da ideia de Contemporaneidade bem como postula a arte contemporânea como um corpus de

\footnotetext{
${ }^{1}$ Não estamos aqui afirmando que a literatura surda circunscreva-se à produzida em língua de sinais. Compreendemos que há produções em Sign Writting (Escrita de Sinais) e em língua portuguesa (e em outras línguas como a inglesa e francesa, por exemplo) que podem ser consideradas como tal, por abordarem temas conexos às culturas e às identidades surdas. Entretanto, neste artigo, escolhemos como objeto de estudo uma categoria da literatura surda cuja expressão realiza-se através das línguas de sinais, na modalidade visual e espacial.
} 
estudo em construção, inacabado, e que suscita muito mais perguntas do que respostas. Diante de uma globalização que exibe as suas fraturas, pensá-la demandaria um olhar critico, disposto a entender a noção de Contemporaneidade como atrelada a molduras culturais e sociais específicas, embora porosas, e a não aceitar passivamente a falácia de sua homogeneidade.

A perspectiva de Smith (2013) aplica-se à reflexão sobre a literatura surda e ao lugar de sua configuração estética baseada em experiências inovadoras, porque tecidas à margem. Para Bauman, Nelson e Rose (2006), a condição histórica periférica da literatura em línguas de sinais teria sido positiva, pois abriu espaço para uma experimentação artística fora dos padrões literários tradicionais. Na condição de arte periférica, a literatura em língua de sinais inscreve-se no embate e na resistência contra formas tradicionais e excludentes de conceber a literatura, que condicionam o texto literário ao modo escrito ou que não reconhecem a LIBRAS como língua capaz de produzir manifestações literárias.

A posição experimental da literatura em línguas de sinais participa de um contexto global, no qual proliferam manifestações estéticas que rompem com a ideia de especificidade da forma artística; como apontado por Jacques Rancière (2017), em O espectador emancipado, a atualidade da arte contemporânea é marcada pelo fato de que "todas as competências artísticas específicas tendem a sair de seu domínio próprio e a trocar seus lugares e poderes" (RANCIÈRE, 2017, p. 24).

A proposição de Rancière vai ao encontro da perspectiva plural sobre a Contemporaneidade postulada por Smith. A elas também alinha-se a compreensão de Garramuño e Kiffer (2014) sobre a atual ruptura de padrões e normas estéticas, de modo a ser possível afirmar a inespecificidade das formas artísticas contemporâneas (GARRAMUÑO, 2014). Assume-se, assim, a presença de "uma noção de literatura ou de arte que tem incorporado, dentro de sua linguagem, suportes e funções, uma relação com outros discursos e esferas nos quais o literário, ou o artístico, não é dado nem construído, mas, muito pelo contrário, desconstruído ou, pelo menos, colocado em questão" (KIFFER; GARRAMUÑO, 2014, p. 12).

Corroborando com essa perspectiva, Resende (2017) nos lembra que: 
Música, literatura, cinema, teatro, performances, artes visuais, intervenções em espaços públicos ou design recorrem a novos formatos expressivos que esbatem progressivamente as especificidades de suas linguagens. (...) Não se trata mais da adoção da linguagem de uma manifestação artística por outra, em trocas como já ocorreu durante o modernismo entre cinema, teatro, literatura. O termo convergência refere-se a um fluxo de conteúdos que circulam por sistemas midiáticos mas também por fronteiras nacionais e que dependem da participação ativa de usuários e consumidores. Essa transformação cultural modifica fortemente a relação existente no passado entre criador, obra e consumidor de arte (RESENDE, 2017, posição² 83).

Portanto, tanto em termos de meios e formas, quanto de processos de produção, recepção e circulação, a obra de arte na contemporaneidade tem no hibridismo e na inespecificidade suas marcas. E, ainda que persistam os limites impostos pelos jogos de mercado nos processos de valorização, divulgação e recepção das obras estéticas, a convergência e a circularidade da intermidialidade amparam uma organização policêntrica da arte no cenário global pós-moderno (RESENDE, 2017).

Resende (2017) também ressalta que dentro dessa organização destaca-se a ideia de processo, ligada à performance, ao imediato e ao inacabado, em forte conexão com a experiência do fazer teatral. Abre-se espaço para o descentramento e para o empoderamento dos artistas e da produção periférica, com seus novos regimes artísticos, assim como para a "incorporação do convívio com as novas tecnologias" (2017, p. 202).

Dentro desse cenário, voltamos aos lugares ocupados pela literatura surda produzida em línguas de sinais. Experimental, híbrida e inespecífica, ela se apresenta como um processo em construção, conduzido, geralmente, por estratégias de organização poética que se criam pela clave da performance.

Com isso queremos sinalizar para a relação entre a literatura em língua de sinais e a arte da performance. Tal conexão encontra-se na presença, na literatura em língua de sinais, de processos vinculados a aspectos como a liberdade de apresentar a obra em qualquer espaço, a presentificação do sujeito da enunciação e do uso do corpo, em seus movimentos e expressões, como instrumento condutor da literariedade. Podemos afirmar, como propôs Rose (2006), a qualidade de performance da produção literária em língua de sinais, uma vez que sua poética organiza-se através

\footnotetext{
2 Por se tratar de edição Kindle no formato de livro eletrônico, não há referência a páginas, mas a posições.
} 
de um corpo inserido em uma moldura espacial e temporal conexa à visualidade e ao movimento.

É uma literatura que envolve enunciação em línguas de sinais, imagem e cinética, indo ao encontro da ideia de experimentação e imprecisão das definições estéticas presentes na literatura contemporânea (GARRAMUÑO, 2014). Também a consideramos como performance diante da proposição de Leirner (1989), que conceitua esta como "uma pintura sem tela, uma escultura sem matéria, um livro sem escrita, um teatro sem enredo, ou a união de tudo isso", já que sua organização se dá em torno da apreensão e da reorganização de elementos vindos de categorias artísticas diversas em sua constituição.

Queremos também pensar a literatura em língua de sinais pela chave proposta por Néstor Canclini (2003) em relação às culturas na pós-modernidade, marcadas indelevelmente por seu caráter híbrido, de modo a ser insustentável afirmar qualquer produção cultural como pura, estável ou fechada. Com isso propomos refletir sobre a literatura surda como produtora de bens culturais forjados na circularidade de fronteiras culturais, no hibridismo de formas estéticas, e no deslocamento e ressignificação de bens simbólicos advindos de culturas distintas.

Cabe, portanto, compreender as manifestações literárias da cultura surda como inespecíficas e periféricas, marcadas por modos plurais de elaboração e de circulação. A condição periférica da literatura surda vincula-se a sua condição de pertencimento a minorias linguísticas e culturais, falantes de línguas de sinais, de estrutura visual e motora, divorciadas da palavra escrita. A proposição, por parte das comunidades surdas, de uma literatura surda, marcada pela tridimensionalidade e enunciada em uma linguagem verbal fora da escrita, desestabiliza concepções tradicionais acerca do literário, que o propõem como situado exclusivamente em textos grafados.

A situação periférica ocupada pela literatura surda também é conexa ao reconhecimento das línguas de sinais como línguas e não linguagem ou mímica. Embora o reconhecimento das línguas de sinais como línguas já tenha sido defendido pelas pesquisas no campo da Linguística desde a década de sessenta, muitas vezes tal estatuto é desconsiderado por ignorância e preconceito. 
No Brasil, por exemplo, apesar de legalmente reconhecida como língua brasileira, a LIBRAS ainda não é amplamente compreendida dessa forma. A título de ilustração, podemos apontar as reportagens produzidas em 2017 acerca da redação do Exame Nacional de Ensino Médio (ENEM) daquele ano, cujo tema foi o ensino de surdos, o que trouxe visibilidade às políticas públicas sobre as comunidades surdas. Entretanto, várias reportagens e artigos que versavam sobre a prova referiam-se a LIBRAS como "linguagem de sinais" e "linguagem de surdos".

Stokoe $^{3}$ (2006), pioneiro nos estudos sobre as línguas de sinais, destacou:

\begin{abstract}
Quando em 1960 tornou-se claro que a Língua de Sinais americana era sem dúvida uma língua, algo maior do que uma língua veio à superfície. Uma língua não apenas provê a uma comunidade de usuários um meio para se comunicar; ela preserva as suas memórias, envolve as suas esperanças e desejos, e salvaguarda os seus valores - ainda mais quando envolve a arte. A língua de um povo e sua cultura são inseparáveis (...) como são inseparáveis uma língua visual e o papel do corpo na sua expressão (STOKOE, 2016, s.p.) $)^{4}$.
\end{abstract}

Portanto, na expressão literária surda, corpo, língua, movimento e comunicação conjugam-se. Essa conjugação, como dito, será desenvolvida através de estratégias de performance, nas quais formam-se e conformam-se objetos artísticos de uma presença lábil e irrepetível, exceto quando registradas por tecnologias de reprodução da imagem. Criam-se modos de performar o literário em jogos que hibridizam traços dramáticos, narrativos e líricos, bem como outros provenientes das linguagens artísticas da dança, das Artes Plásticas e do cinema.

As línguas de sinais "inscrevendo graficamente uma "escrita do/no corpo" (BAUMAN, NELSON e ROSE, 2006) situam-se em uma posição de vanguarda ao produzirem uma literatura que anunciou uma mudança de paradigmas nos processos de comunicação que vieram a se desenvolver a partir do final dos anos noventa. Como postula Kress (2003), esse foi o momento em que houve uma guinada profunda no modo e no meio predominantes de comunicação - o domínio da escrita e do livro foram superados pelo uso da imagem e da tela.

\footnotetext{
${ }^{3}$ Este é um trecho de um texto com publicação póstuma de Willian Stokoe, usado como prólogo no livro Signing the Body Poetic: Essays on American Sign Language Literature (2006).

${ }^{4}$ When in 1960 it became clear that American Sign Language (ASL) is indeed a language, something more than a language emerged from underground. A language does not just provide a community of users with a way to communicate; it preserves their memories, encapsulates their hopes and desires, and safeguards their values-all the more so when its use involves art. A people's language and culture are inseparable, so this volume exploring ASL literature is doubly welcome (STOKOE, 2016, s.p.)
} 
Alinhamos essa percepção à de Bauman, Nelson e Rose (2006), ao pensarem a inserção da produção literária surda dentro desse contexto e perceberem que esta já encenava o deslocamento do entendimento da obra literária como restrita à produção escrita e oral para uma compreensão calcada no modelo de performance e na intertextualidade do literário com o campo visual e pictórico.

Logo, consideramos a literatura surda em língua de sinais uma produção artística híbrida, inscrita em processos conexos à pós-modernidade, e capaz de reconfigurar conceitos e práticas concernentes ao literário ao colocar em cena uma literatura de amparo visual, que transforma o uso cotidiano do corpo "na forma cinética e na pele do poema". Em face a isso, "ler torna-se ver, livros tornam-se vídeos, e papéis tornamse um corpo em performance. Literalmente, essa é uma forma de "escrever-o-corpo", o corpo do poeta torna-se um palimpsesto sobre o qual se desenvolve as imagens cinéticas tridimensionais do signo" (BAUMAN; NELSON; ROSE, p. 2, 2006).

Diante do exposto, faremos aqui um mapeamento da categoria da literatura em língua de sinais Visual Vernacular (VV). Consideramos seu estudo relevante, por ser essa uma expressão da literatura surda construída de forma inovadora, que ainda clama por estudos. Como a VV está ligada intrinsecamente às identidades e às culturas surdas, o seu estudo é uma forma de valorizá-las como construtoras de arquiteturas estéticas experimentais, mas que interessam também a qualquer um que manifeste interesse sobre formas alternativas na arte literária contemporânea, pela chave de seu entendimento como plural, instável e aberta a experimentações.

A Visual Vernacular é uma forma estética performática e narrativa, produzida a partir das línguas de sinais, mas que, propositalmente, usa poucos sinais padronizados - e, por vezes, nenhum. Ela propõe a articulação desses poucos sinais relacionada à percepção de classificadores ${ }^{5}$. Caracteriza-se pela elaboração de processos narrativos em terceira dimensão, através do uso de elementos e estratégias da linguagem cinematográfica. Hibridiza-se, ainda, com a poesia, o teatro, a mímica e a dança, mesclando-os em sua estrutura.

Em relação ao surgimento da Visual Vernacular, percebemos que existem relatos de surdos americanos sobre a emergência desta forma artística, no contexto

\footnotetext{
${ }^{5}$ Classificadores referem-se a configurações de mãos que funcionam como morfemas e identificam características de um objeto nas línguas de sinais (FELIPE, 2012).
} 
dos falantes de ASL, que se apresenta de modo muito similar às narrativas de surdos brasileiros, no contexto das comunidades de surdos falantes de LIBRAS.

Os americanos contam que a Visual Vernacular nasceu com os relatos dos surdos sobre filmes (SUTTON-SPENCE, KANEKO, 2016, p. 62). De modo similar, no Brasil, há relatos nos discursos sociais que circulam nas comunidades surdas que situam a origem da Visual Vernacular na década de 50, em um momento em que o Instituto Nacional de Educação de Surdos - o INES - tinha alunos internos pobres. Seus colegas em melhores condições financeiras iam ao cinema, geralmente para verem filmes de Faroeste, e, ao retornarem ao INES, Ihes contavam o que haviam visto nos filmes, em recontos realizados, principalmente, através de classificadores.

Entretanto, ao pensarmos na Visual Vernacular como arte sistematizada, vimos nos estudos de Bauman (2006) que o surgimento desta categoria aponta-a como criação do artista surdo Bernard Bragg, ator ligado ao Teatro Nacional do Surdo, nos Estados Unidos. Segundo Bauman (2006), entre os anos de 1967 e 1977, Bragg começou a divulgar, informalmente, o seu trabalho entre artistas surdos americanos, explorando possibilidades artísticas da língua de sinais americana.

Bragg estabeleceu uma ruptura criativa no que concerne ao emprego estético das línguas de sinais, ao elaborar a técnica performática da Visual Vernacular, cujo nome se explicaria por sua ligação com "os códigos vernaculares da mídia cinematográfica" (BAUMAN, 2006, p. 110).

De acordo com o ator, a criação da VV deu-se a partir de um curso de mímica do qual participou, em Paris, a convite de Marcel Marceau. Apesar do curso de mímica ter catalisado o desenvolvimento da categoria, Bragg (APUD SUTTON-SPENCE, KANEKO, 2016, p. 61.) a situa fora da estrutura da mímica tradicional, pois a VV, no processo de performance, seleciona e usa um espaço menor para a enunciação da narrativa; e como performance, pode ser encenada em qualquer espaço físico ou ser apresentada na forma de registro em vídeo.

Bragg defende a peculiaridade estética da Visual Vernacular em relação à mímica, embora alguns elementos desta, como destacou, integrem a construção da VV. Para ele, a VV não é mímica em si, mas uma narrativa ancorada na visualidade e no movimento. 
Sutton-Spence e Kanenko (2016) afirmam que, segundo esclarecimento do próprio, Bragg adaptou a mímica para que esta coubesse na língua de sinais. As pesquisadoras, da mesma forma, evidenciaram traços diferenciadores das categorias mímica e Visual Vernacular (SUTTON-SPENCE, KANEKO, 2016, p. 65), os quais sintetizamos no quadro a seguir:

\begin{tabular}{|c|c|}
\hline MÍMICA & VISUAL-VERNACULAR \\
\hline $\begin{array}{l}\text { Transmite ações e emoções através de } \\
\text { gestos, sem base verbal, o que a torna } \\
\text { compreensível a falantes de várias } \\
\text { línguas. }\end{array}$ & $\begin{array}{l}\text { Tem base verbal, pois emprega, ainda que } \\
\text { pouco, as línguas de sinais. }\end{array}$ \\
\hline O corpo inteiro é usado. & $\begin{array}{l}\text { A sinalização raramente ocorre abaixo dos } \\
\text { quadris. }\end{array}$ \\
\hline $\begin{array}{l}\text { O mímico desloca-se e circula pelo } \\
\text { espaço da apresentação, para demonstrar } \\
\text { os percursos das personagens. Usa toda } \\
\text { a extensão do espaço vertical, incluindo o } \\
\text { chão. }\end{array}$ & $\begin{array}{l}\text { O sinalizador permanece em um mesmo } \\
\text { lugar e demonstra os percursos das } \\
\text { personagens com movimentos das mãos } \\
\text { e do restante do corpo, mas sem } \\
\text { atravessar o espaço da apresentação. }\end{array}$ \\
\hline $\begin{array}{l}\text { A encenação da mímica tende a ser mais } \\
\text { extensa, sem cortes rápidos. }\end{array}$ & $\begin{array}{l}\text { O sinalizador incorpora as perspectivas do } \\
\text { narrador e das personagens, além da } \\
\text { representação do cenário, alternando-os } \\
\text { durante a narração, em cortes contínuos e } \\
\text { rápidos. Dessa maneira, há referências a } \\
\text { enquadramentos cruzados, que usam o } \\
\text { close-up, o plano médio, e o plano aberto, } \\
\text { por vezes, simultaneamente. }\end{array}$ \\
\hline
\end{tabular}


Face ao supracitado, conclui-se que, apesar de trazer em si elementos da mímica, a Visual Vernacular é um fazer artístico diverso desta.

É importante notar que o surgimento das novas tecnologias permitiu a vários artistas, além de Bragg, a produção e divulgação da Visual Vernacular em vídeos nas redes sociais, valendo-se de procedimentos oriundos da linguagem cinematográfica para gerar sentidos poéticos, como a sobreposição de imagens, a aceleração ou a diminuição da velocidade do filme e o emprego de imagens borradas. Através de movimentos contínuos e gradações de velocidade são impressas significações e ritmos à narrativa. Nosso interesse aponta, justamente, para essas produções da Visual Vernacular disponibilizadas em vídeo e criadas a partir dos anos 2000, em um momento no qual o acesso às novas Tecnologias de Informação permitiu o desenvolvimento de uma arte fundada na intermidialidade.

Concebemos intermidialidade como referente aos fenômenos que derivam dos cruzamentos entre mídias. Alinhados ao pensamento de Rajewsky (2012), admitimos a necessidade de especificar categorias para as concepções sobre os fenômenos intermidiáticos, uma vez que "a intermidialidade não é uma função fixa uniforme. Ela analisa exemplos individuais em relação a sua especificidade, levando em consideração possibilidades historicamente mutantes para a funcionalização das práticas intermidiáticas" (RAJEWSKY, 2012, p. 33).

Dessa feita, se postulamos a Visual Vernacular como prática estética que conduz a sua performance pela expressão visual e motora, concernente às línguas de sinais, percebemos também tal condução através de relações intermidiáticas entre um corpo que se expressa pelos modos cinético, espacial e linguístico e as mídias do teatro e, sobretudo, do cinema.

Consideramos tais relações como pertencentes a duas categorias de intermidialidade elencadas por Rajewsky (2012): a combinação de mídias e as referências intermidiáticas, pois como produto estético fundado na intermidialidade, a Visual Vernacular combina as mídias do teatro e do vídeo em sua produção, ao passo que também inclui em sua constituição referências estéticas a elementos que compõem a sintaxe do cinema.

Assim, aplica-se nas supracitadas relações o conceito de Rajewsky (2012) de intermidialidade por referência, uma vez que a Visual Vernacular emprega "técnicas 
cinematográficas como tomadas em zoom, dissolvências, fades e edição de montagem" (RAJEWSKY, 2012, p. 35). Cabe, aqui, resgatar a afirmação de Resende (2016) sobre as relações entre artes presentes na estética contemporânea como não apenas troca ou adoção, mas como convergência mesmo.

Portanto, a Visual Vernacular é uma forma literária predominantemente narrativa, tecida como ação através de movimentos, sinais, gestos e expressões que emulam os movimentos da câmera cinematográfica, como o close, a visão panorâmica e várias formas de enquadramento. Geralmente, narra uma história sucinta, em um arco que demonstra um processo de transformação de uma situação, na maioria das vezes em torno de um enredo baseado na estrutura clássica narrativa - situação inicial, problema, clímax e epílogo.

Todavia, ao mesmo tempo que absorve elementos da literatura tradicional, a Visual Vernacular os transcende na sua proposição formal intermidiática e performática, narrando através de elementos dramáticos e cinematográficos, assim como pelo uso de movimentos corporais, sinais, classificadores e expressões faciais. Pela emulação da técnica cinematográfica dos cortes de cena e da montagem, o sujeito sinalizador assume o lugar de narrador e, simultaneamente, a perspectiva das personagens e a representação do cenário, alternando focos diferentes da ação e da cena.

O sujeito que enuncia a história alterna-se nos papéis de narrador e de personagem, e conduz o cenário narrativo. Muitas vezes, é ele também o responsável pela gravação da performance e pela edição do vídeo. Nas apresentações ao vivo, a Visual Vernacular constrói um espaço simbólico e personagens que desenvolverão nele uma história através do uso de sinais, classificadores e expressões visuais. O narrador assume, ao mesmo tempo, a enunciação e a representação do espaço/cenário e das personagens, sobrepondo os três elementos. Muitas vezes, é também o sujeito sinalizador o responsável pela gravação da performance e pela edição de seu vídeo.

É importante ressaltar que, apesar de abarcar traços de linguagens distintas, a Visual Vernacular não apenas dialoga com elas, mas as assume na coordenação de sua própria forma estética, constituindo-se como manifestação artística com traços 
distintivos. Um deles é o fato de usar poucos sinais padronizados, intencionalmente, optando pelo emprego predominante de classificadores.

Como arte performática, ela é tecida por vários modos produtores de semioses, pelos quais se expressa na relação tempo e espaço, através da visualidade e da experiência motora, e na já referida presentificação, pois, como performance, ocorre como um processo contínuo que se apresenta ao público a partir de uma perspectiva tridimensional e icônica, ao usar classificadores e movimentos corporais e faciais altamente expressivos.

Assim, ela está inscrita no contexto apontado pelas pesquisas de Bauman (2006) que identificam o intenso e profícuo diálogo entre a literatura de língua de sinais e a linguagem cinematográfica. Para o pesquisador, as formas artísticas em língua de sinais criam imagens em movimento capazes de emularem técnicas usadas em filmes, o que vai ao encontro de nossa percepção sobre o aspecto inermidiático presente na Visual Vernacular, como referido.

Bauman considera as produções em Visual Vernacular gravadas em vídeo como performances cinematográficas, pois o artista criador, além de ser o enunciador (sinalizador, na proposição de Bauman) e incorporar posições de narrador, personagem e cenário, também filma e edita a obra, como mencionamos.

Completam tal pensamento os estudos de Zaghetto (2018), para quem as composições de Visual Vernacular são comparáveis a filmes mudos ou imagenssequência, por seu estilo basear-se no uso de classificadores, expressões faciais e técnicas de incorporação suportadas por um plano motor específico, o qual cria um ritmo peculiar de articulação de sinais, geralmente rápido, que caracteriza as performances da VV.

Para melhor compreender a poética da Visual Vernacular, gostaríamos de propor uma breve leitura analítica do vídeo "Caterpillar" (Lagarta), criado por lan Sanborn, em 2014. Ele é um professor e artista surdo, participante há anos do Teatro Nacional do Surdo, nos Estados Unidos.

"Caterpillar" abre-se diante de um cenário em preto e branco, com a imagem frontal de lan Sanborn, que irá narrar e, concomitantemente, representar o espaço da narrativa e a personagem. Trata-se de um texto com traços híbridos, líricos e narrativos, uma espécie de poema narrativo. 
Como notado por Sutton-Spence e Kaneko (2016) em relação à literatura em línguas de sinais, o narrador de Sanborn representa esses elementos da narrativa sem usar a extensão integral do espaço vertical ou se deslocar pelo espaço da encenação, usando pouco espaço físico cênico. O enquadramento presente na performance poética pode ser percebido como similar tanto ao espaço utilizado para a comunicação em língua de sinais, dos quadris para cima, quanto ao do meio primeiro plano, dentro da linguagem cinematográfica, que representa a imagem da cintura para cima.

Inicialmente, o narrador aparece e apresenta o título da obra, em dactilologia (Fig.1).

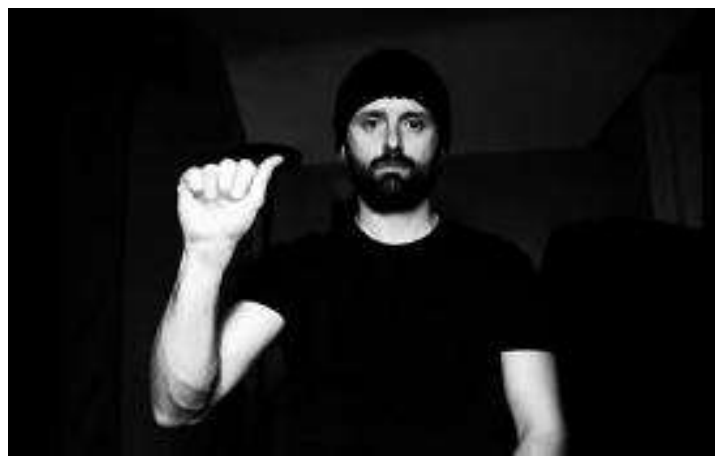

Fig. 1

Sua expressão é neutra e será assim mantida durante boa parte da apresentação, propositalmente. A neutralidade do narrador o distancia da narrativa, neste primeiro momento. As suas roupas são pretas e fundem-se ao cenário físico, ratificando a ideia de neutralidade do foco narrativo, a fim de colocar em primeiro plano a história a narrar.

Ele indica com as mãos um espaço limitado e plano. Posteriormente, faz um gesto vertical em ascensão com o dedo indicador. Na sequência, usa-se o recurso tecnológico de aceleração da velocidade da imagem, de modo a figurar a passagem do tempo. Há um jogo de imagens que alterna aceleração e lentidão. Imprime-se, pela via da velocidade e do corpo e da imagem movente, registrados na tela, ritmos elaborados pelo movimento e não pelo som. Alia-se tal elaboração ao que se percebe 
como a ausência de paradoxo na expressão "música silenciosa", presente nas poesias em línguas de sinais (BAUMAN, NELSON, ROSE, 2006).

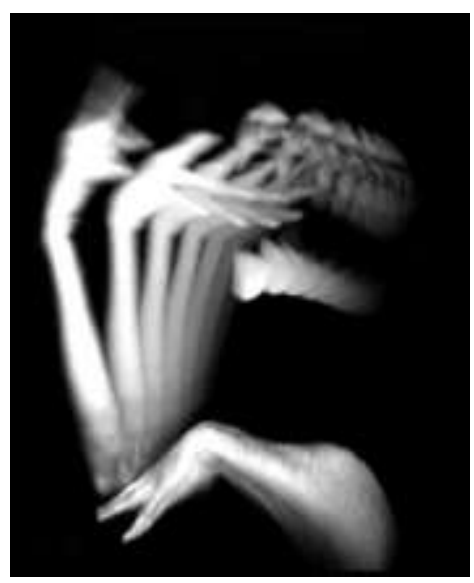

Fig. 2

Compreende-se que o espaço limitado e plano demonstrado pelo narrador é o solo e que o movimento ascendente do dedo indicador indica o crescimento de uma árvore. O narrador representa o sol com uma das mãos e com a outra simula um movimento contínuo de subida, acelerado pela edição do video (Fig. 2), de modo a representar a velocidade da passagem do tempo para demonstrar que "um dia" algo aconteceu, em diálogo com a imprecisão temporal típica das narrativas primordiais. Aparece, a partir desse ponto, a personagem da narrativa, a lagarta.

Com o uso de classificadores, figura-se o corpo da lagarta, com as suas patas e antenas, que anda em direção à árvore. Os três elementos - narrador, personagem e cenário - são apresentados simultaneamente.

A mão direita, ao representar a árvore, fica parada, em contraste ao movimento da personagem. Na representação da ida da lagarta até a árvore o narrador faz movimentos horizontais da esquerda para a direita, mostrando a personagem no cenário, que se alternam a movimentos verticais no centro, os quais se referem à personagem, somente. Assim são apresentadas imagens entrelaçadas em movimentos que se alternam entre a representação da personagem e do cenário, simulando um plano de conjunto, e a imagem da personagem, em close-up.

Complementam a performance narrativa as expressões faciais, o movimento e a velocidade, como dissemos, presentes, por exemplo, nas expressões faciais de 
surpresa (quando a lagarta vira uma borboleta com asas); no olhar do ator/narrador direcionado para o que está acontecendo, virando a cabeça para direita e esquerda, e olhando o surgimento das asas; nos movimentos com a mão criando velocidade e ritmo diferenciados: devagar, quando a lagarta anda até a árvore, lentamente, ou mais velozes, quando as mãos giram rapidamente durante a metamorfose.

A partir do momento em que o narrador representa a chegada da lagarta à árvore, ele mantém o movimento ao centro, simulando a justaposição entre o cenário e a personagem, já que esta tenta escalar o tronco da árvore, e ele figura, em movimentos alternados que simulam vários planos - geral, médio e close-up - tanto os passos da lagarta, quanto a imagem do espaço narrativo, no qual ela está inserida. Primeiro, apresenta-se uma imagem similar à do plano médio. Depois, volta-se à simulação do plano de conjunto, pelo movimento horizontal da lagarta até a árvore.

Começa-se, então, a figurar a alternância entre os três planos de representação - geral, médio e close-up, ao narrar a chegada da lagarta a um galho da árvore, representado pelo narrador através do polegar da mão estática que forma a imagem da árvore. A lagarta enrosca-se em um fio e verifica a sua firmeza. Nesse momento, utiliza-se o slow motion. A lagarta pendura-se no galho e tece o casulo. O ritmo lento imprime um sentido de dificuldade e esforço à representação.

A tessitura do casulo demarca a mudança na narrativa. Alterna-se a imagem em velocidade normal, simulando em plano médio a lagarta na árvore, à imagem em velocidade acelerada, simulando em close-up a lagarta enrolando-se no casulo. Alternam-se planos e velocidades na representação do tempo - normal, lenta e acelerada - conforme a transformação da lagarta em borboleta acontece (Fig. 3).

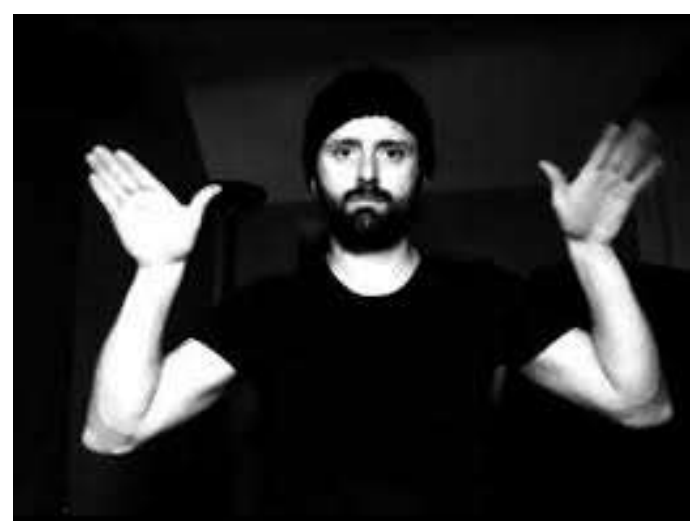

Fig. 3

Pensares em Revista, São Gonçalo-RJ, n. 12, p. 56-75, 2018.

DOI:10.12957/pr.2018.34059 
Com a transformação da lagarta em borboleta, a narrativa passa a simular 0 plano close-up. O narrador forma com uma das mãos e braços uma asa, e com a outra mão e braço a outra asa. Em seguida, olha para cada uma das asas e sorri. Rompese a sua neutralidade e acontece uma espécie de simbiose entre o narrador e a personagem - um laivo da linguagem lírica participando de uma narrativa já híbrida.

Pode-se observar que a narrativa apresenta até o momento da metamorfose o foco centrado nas mãos e nos braços do narrador, representando um período que demonstra os desafios da lagarta, que pode ser visto como difícil e tenso. O narrador só quebra a sua neutralidade após notar o surgimento das asas. Sua simbiose com a borboleta, par e passo ao momento em que o vídeo deixa de ser em preto e branco e se torna colorido, ocorre quando a borboleta consegue voar, demonstrando algo positivo, um bom momento, de vitória e satisfação.

No momento da metamorfose, portanto, o vídeo colore-se e os movimentos intensificam-se. Cor e velocidade organizam-se como índices da alegria e da liberdade ligados à persona da borboleta/narrador. Há a incorporação, pelo uso de classificadores feitos com as mãos e os braços do narrador, da imagem da borboleta voando - nos outros momentos, a incorporação da borboleta era feita só pelo movimento das mãos.

Finaliza-se o arco da narrativa, em um gradiente que percorreu da ausência de cor ao colorido; do esforço à recompensa; da dificuldade à libertação; do afastamento e neutralidade iniciais do narrador a sua fusão à imagem da borboleta. Ao incorporar a personagem, alcança o narrador, junto a ela, também a sua metamorfose.

Em "Caterpillar" tornam-se nítidos os recursos postulados pela Visual Vernacular, especialmente a predominância na narrativa do uso de classificadores, como os que criam significações referentes ao movimento de crescimento da árvore, às partes do corpo da lagarta, ao casulo em construção, e às asas da borboleta.

Percebemos como a Visual Vernacular converge com a linguagem do cinema, simulando no processo de narração de histórias seus enquadramentos, e inserindo técnicas provenientes do vídeo para a construção de semioses ligadas à representação do enredo, das personagens, do tempo e do espaço. Ela usa expressões imaginativas próprias das línguas de sinais e organiza modos produtores 
de sentidos, através da ideia de presentificação, já que acontece como ação, como processo que se apresenta ao público a partir de uma perspectiva intermidiática.

Por fim, gostaríamos de sublinhar que por ser a Visual Vernacular uma expressão estética que compreende o conceito de texto literário como plural e aberto a formas artísticas não tradicionais, consideramos como fundamental a produção de mais pesquisas sobre esta categoria, uma vez que a divulgação da VV interessa tanto especificamente aos pesquisadores da área de Estudos Surdos, como a qualquer interessado em arte contemporânea, em sua condição experimental e plural.

\section{Referências Bibliográficas}

BABHA, H. The Location of Culture. London: Routledge, 1994.

BAUMAN, D.; NELSON, J. E ROSE, H. Introduction. In: BAUMAN, D.; NELSON, J. E ROSE, H.Signing the Body Poetic: Essays on American Sign Language Literature. Los Angeles: University of California Press, 2006.

BAUMAN, D. Getting out of Line: Toward a Visual and Cinematic Theory. In: BAUMAN, D.; NELSON, J. E ROSE, H. Signing the Body Poetic: Essays on American Sign Language Literature. Los Angeles: University of California Press, 2006.

BRASIL. LEI n.10.436/2002. Disponível em: <http//:planalto.gov.br>. Acesso em: 10 fevereiro 2015.

CANCLINI, N. G. Culturas híbridas. São Paulo: EdUSP, 2006.

FELIPE. T. Sistema de Flexão Verbal na LIBRAS: Os classificadores enquanto marcadores de flexão de gênero. Anais do Congresso Surdez e Pós-Modernidade: Novos rumos para a educação brasileira. Rio de Janeiro: INES, 2002.

GARRAMUÑO, F. Frutos Estranhos: sobre a inespecificidade na estética contemporânea. Rio de Janeiro: Rocco, 2014.

HALL, S. A identidade cultural na pós-modernidade. Rio de Janeiro: DP\&A, 2005.

KIFFER, A. e GARRAMUÑO, F. Expansões contemporâneas: Literatura e outras formas. Belo Horizonte: Editora da UFMG, 2014.

KRESS, G. Literacy in the new media age. London: Routledge, 2003.

Multimodality. A social semiotic approach to contemporary communication. New York: Routledge, 2010. 2006.

Reading images: the grammar of visual design. London; New York: Routledge, 
LUCZAK, R. Silence Is a Four-Letter Word: on Art \& Deafness. Minneapolis: Handtype Press, 2012.

PEREIRA, D. M.; ABRAHÃO, B. F. O direito do surdo à literatura: por uma educação literária multimodal. Linguagem em (Re)vista, vol. 10, n. 20. Niterói, jul./dez. 2015.

RANCIÈRE, J. O espectador emancipado. São Paulo: Martins Fontes, 2017.

RAJEWSKY, I. O. Intermidialidade, intertextualidade e "remediação": uma perspectiva literária sobre intermidialidade. In: DINIZ, Thaïs Flores Nogueira (Org.). Intermidialidades e estudos interartes: desafios da arte contemporânea. Belo Horizonte: UFMG, 2012.

RESENDE, B. Poéticas do contemporâneo. Rio de Janeiro: E-galáxias, Laboratório da palavra UFRJ, 2017 - Edição para Kindle.

ROSE, $\mathrm{H}$. The poet in the poem in the performance. In: BAUMAN, D.; NELSON, J. E ROSE, H. Signing the Body Poetic: Essays on American Sign Language Literature. Los Angeles: University of California Press, 2006.

SANBORN, I. $\quad$ Caterpillar. 2014. Disponível em: <https://www.youtube.com/watch?v=MTgGQnxX5Uw>. Acesso em 20 abril 2018.

SACKS, O. Vendo Vozes - uma viagem ao mundo dos surdos. São Paulo: Companhia das Letras, 2013.

SILVA, A. G. Corpo-texto, texto-corpo: apontamentos sobre literatura e performance na contação de história em língua de sinais. RBLA, Belo Horizonte, v. 17, n. 4, p. 793812,2017

SKLIAR, Carlos. A surdez: um olhar sobre as diferenças. Porto Alegre: Mediação, 2013.

SMITH, T. ""Our" Contemporaneity?". DUMBADZE, Alexander; Suzanne Hudson. Contemporary Art - 1989 to the present. West Sussex: John Wiley and Sons, 2013.

SUTTON-SPENCE, R.; KANEKO, M. Introducing Sign Language Literature: Folklore and Creativity. Palgrave Macmillan, 2016 - versão Kindle.

STOKOE, W. F. In: BAUMAN, D.; NELSON, J. E ROSE, H.Signing the Body Poetic: Essays on American Sign Language Literature. Los Angeles: University of California Press, 2006.

ZAGHETTO, A. Musical Visual Vernacular. How the deaf people translate the sound vibrations into the sign language: an example from Italy. In: Signata. Annales des Sémiothiques. Disponível em:

$<$ https://journals.openedition.org/signata/934?lang=en>. Acesso em: 20 abril 2018. 


Sobre os autores
Danielle Cristina Mendes Pereira Ramos
Doutora em Literatura Comparada pela Universidade Federal Fluminense (2006). Como professora
adjunta da Faculdade de Letras da Universidade Federal do Rio de Janeiro, atua no Departamento
de Letras-LIBRAS, no setor de Estudos Literários, e nos cursos de Pós-Graduação em LIBRAS e
em Literatura Infantil, onde ministra a disciplina Literatura e Imagem. Autora de livros e artigos,
publicados no Brasil e no exterior, desenvolve pesquisa em torno dos seguintes temas: literatura e
memória; relações entre literatura e visualidade, e representações estéticas de culturas surdas,
dentro do cenário da Pós-Modernidade. Atualmente, participa do grupo de pesquisa Linguagem e
Sociedade (FFP-UERJ) e coordena o projeto de extensão Imagens Surdas.
Bruno Abrahão
Professor e pesquisador surdo, Bruno Ferreira Abrahão é especialista em LIBRAS e mestrando em
Ciência da Literatura na Universidade Federal do Rio de Janeiro. Atua como professor auxiliar na
Faculdade de Letras da mesma instituição, no Setor de LIBRAS do Departamento de Letras-
LIBRAS, onde é responsável pelas disciplinas de Literatura Surda e Escrita de Sinais, e na Pós-
Graduação em LIBRAS. Desenvolve pesquisa sobre LIBRAS e letramento para surdos, por meio
de contos e fábulas, poesia surda e contemporânea, especialmente sobre Visual Vernacular,
Poesia Concreta, Poesia A-Z, SLAM de Poesia e Poema Processo. É autor de "Direito do surdo à
literatura", em coautoria.

